\title{
Hamartoma of the Larynx: An Unusual Cause of Stridor 2
}

\author{
Şit Uçar, Pelin Zorlu, Işı1 Yıldırım, Özge Metin \\ Department of Pediatrics, Dr. Sami Ulus Maternity and Children's Health and Diseases Training and Research Hospital, Ankara, Turkey
}

Background: Hamartoma of the larynx is a very rare lesion, and the number of reported cases is limited. Signs and symptoms include stridor, changes in voice, eating and respiratory complaints. Stridor is a sign of upper airway obstruction. Patients presenting with stridor and severe respiratory distress necessitate urgent otolaryngologic evaluation.

Case Report: Herein, we report a case of laryngeal hamartoma presenting with recurrent pneumonia and persistent stridor in a 7-monthold patient. He was admitted to hospital with the initial diagnosis of recurrent pneumonia and persistent stridor. Stridor was not responsive to cool mist, nebulised epinephrine or dexamethasone. Cervical computed tomography $(\mathrm{CT})$ revealed a solid, nodular mass on the posterolateral wall of larynx. The mass was excised surgically. After surgical removal of the hamartoma, the child was relieved of the obstruction.

Conclusion: We want to emphasise that patients presenting with persistent stridor and severe distress necessitate urgent otolaryngologic evaluation.

Key Words: Hamartoma, infant, respiratory sounds, stridor
A hamartoma is characterised by the formation of a tumourlike mass, composed of disorganised, but mature specialised cells or tissue elements that are indigenous to the location where it is found (1). Hamartomas may occur in any organ, but are most commonly found in the lungs, kidney and intestine (2). Hamartoma of the larynx is a very rare, non-neoplastic developmental anomaly that may present clinically with symptoms of upper respiratory tract obstruction, dysphonia, choking, hoarseness and progressive, persistent stridor (3). Twelve cases of laryngeal hamartomas have been reported to date. Although the signs and symptoms of laryngeal hamartoma are variable, they usually include upper airway obstruction and some degree of voice change (4). We report a case of laryngeal hamartoma, an unusual cause of persistent stridor. Informed consent form was obtained from the parents.

\section{CASE PRESENTATION}

A 7-month-old boy was referred for evaluation of tachypnoea, cyanosis, stridor, hoarseness and dysphonia. He had two episodes of pneumonia and one episode of tracheobronchitis. Symptoms of stridor, hoarseness and dysphonia started when he was three months old; grunting, difficulty of feeding, episodic cyanosis and severe respiratory distress became evident in the last two months.

He was the full-term product of an uncomplicated pregnancy and delivery. Family history was insignificant. He was an undernourished male with weight in the 3rd and length in the 50th percentile for age. On physical examination, the patient was dyspnoeic, irritable and had a rough, brassy cough (Video 1. See corresponding video/movie images at www.balkanmedicaljournal.org). Vital signs included heart rate 150/ min, respiratory rate $54 / \mathrm{min}$, blood pressure $90 / 60 \mathrm{~mm} \mathrm{Hg}$, and temperature $36.5^{\circ} \mathrm{C}$. Oxygen saturation in room air was $97 \%$. He had intercostal, subcostal and suprasternal retractions with flaring of the nostrils. His neck was hyperextended and he had biphasic stridor. On auscultation, his breath sounds were slightly coarse without crackles or rhonchi. Cardiac examination revealed a grade II pansystolic cardiac murmur. The rest of his physical examination was normal.

Blood analysis revealed haemoglobin level of $8.7 \mathrm{~g} / \mathrm{dL}$, MCV of $58 \mathrm{fL}$, white blood cell count of $8.7 \times 10^{3} / \mathrm{mm}^{3}$. The peripheral blood smear revealed microcytosis, anisopoikilocytosis and hypochromia. Serum iron level was $12.4 \mu \mathrm{g} / \mathrm{dL}$, the iron-binding capacity of the serum was $386 \mu \mathrm{g} / \mathrm{dL}$, and serum ferritin was $<3 \mathrm{ng} / \mathrm{mL}$; all consistent with iron-deficiency anaemia. The liver and renal function tests, the electrolyte

Address for Correspondence: Dr. Şit Uçar, Department of Pediatrics, Dr. Sami Ulus Maternity and Children's Health and Diseases Training and Research Hospital, Ankara, Turkey Phone: +903123056194 e-mail: situcar@mynet.com 


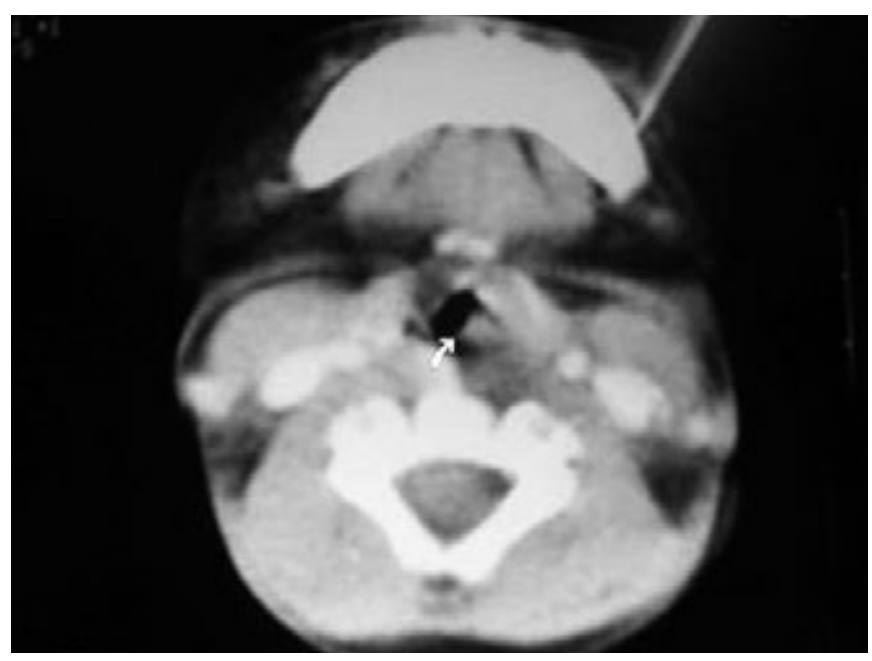

FIG. 1. Preoperative cervical CT revealing a mass lesion of $0.3 \mathrm{~mm}$ on the posterolateral wall of the larynx

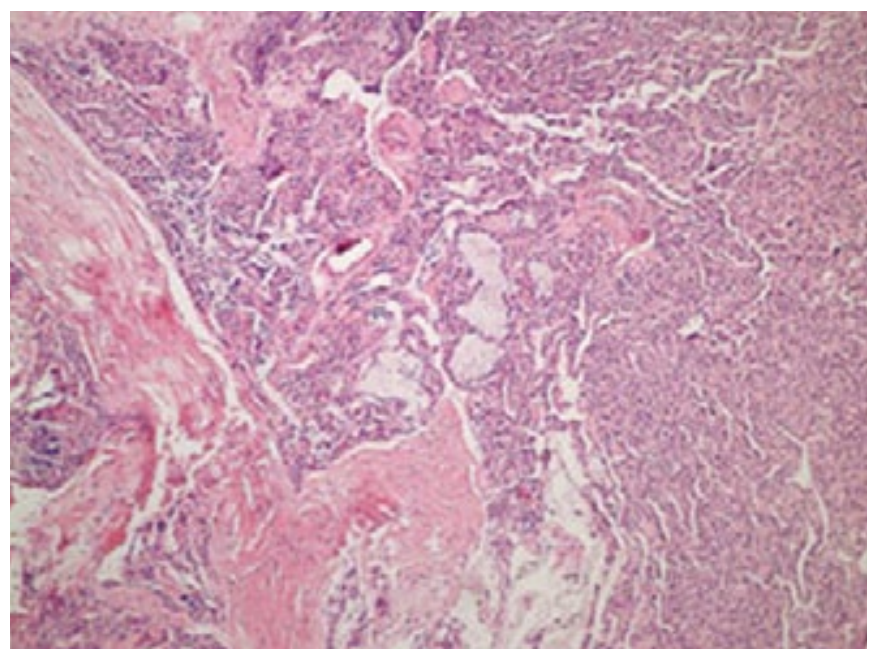

FIG. 2. Well organised smooth muscle fibres with mucous glands and irregular-sized blood vessels in the biopsy specimens. H\&E. X100

levels, C-reactive protein and arterial blood gas analysis were normal. Chest radiograph was nonspecific. Viral serology for respiratory syncytial virus, adenovirus and parainfluenza virus was negative. Culture of nasopharyngeal swab for human metapneumovirus and influenza virus was negative. Intradermal tuberculin testing was non-reactive, serum immunoglobulin levels and sweat chloride tests were normal. Echocardiography revealed non-complicated ventriculoseptal defect without pulmonary hypertension.

He was admitted to the hospital with the initial diagnosis of recurrent pneumonia, persistent stridor and iron deficiency anaemia. Ferrous sulphate was started for iron deficiency anaemia. Stridor was not responsive to cool mist, nebulised epinephrine or dexamethasone. Cervical computed tomography (CT) (Somatom definition as; Siemens, München, Ger- many) revealed a solid, nodular mass of $0.3 \mathrm{~cm}$ on the posterolateral wall of larynx (Figure 1). He was referred to an otolaryngologist and a polypoid, hyperaemic, submucosal lesion protruding into the lumen below the vocal cords was seen by but could not be excised with bronchoscopy. The mass was resected and a tracheostomy tube was placed under general anaesthesia. Biopsy of the mass revealed well-organised smooth muscle fibres admixed with mucous glands and vascular structures consistent with hamartoma (Figure 2). He was decannulated two months later, and his stridor and symptoms of upper respiratory tract obstruction gradually improved postoperatively.

\section{DISCUSSION}

Stridor is an abnormal, high-pitched, musical breathing sound caused by partial obstruction of the upper respiratory tract. In children, laryngomalacia is the most common cause of chronic stridor (3). Causes of stridor can be grouped according to the site of obstruction. Obstruction in the larynx may be caused by laryngomalacia, laryngeal web/cyst or laryngocele, vocal cord paralysis, laryngeal papilloma and other tumours, subglottic haemangioma, foreign body aspiration and post-intubation stenosis. Tracheomalacia, endotracheal tumours and external compression may cause tracheal obstruction and lead to persistent stridor (5).

Clinical evaluation of a child with persistent stridor includes a detailed history, complete physical examination, radiographic studies and referral to an otolaryngologist for examination of the larynx with both flexible and direct techniques (6). Detailed history should include the onset of stridor, factors aggravating it, such as upper respiratory tract infection, supine position, crying and coexisting symptoms such as cyanosis, or difficulty in feeding. Computerised tomography or magnetic resonance imaging may be more helpful in demonstrating mass lesions. However, endoscopic techniques are needed most of the time for a definitive diagnosis. Furthermore, it allows the physician to perform a biopsy and endoscopic removal of the lesion if possible (7).

Treatment depends on the underlying reason for stridor. Most cases of laryngomalacia are managed with watchful waiting; however, surgical intervention is needed for severe cases of laryngomalacia, and other causes compromising respiration (8). Management of laryngeal hamartomas consists of conservative surgical excision (7). Endoscopic removal is usually adequate; however, larger lesions require open techniques for removal, as seen in our case (8).

Our patient presented with stridor and severe airway distress, evidenced by the use of accessory respiratory muscles 
and tachypnoea. Differential diagnoses on admission included pneumonia and congenital heart disease; however, since his lung sounds were clear, there was no infiltration on chest radiograph, acute phase reactants were low, and the viral serology was negative, pneumonia was ruled out. He had a history of two pneumonias and one tracheabronchitis; therefore, cystic fibrosis, immune deficiency and tuberculosis were investigated and excluded with the sweat chloride test, serum immunoglobulin levels and intradermal tuberculin test. Exacerbations of respiratory symptoms may be encountered during upper respiratory tract infections, and the patient might have been over-diagnosed with pneumonia and tracheabronchitis due to the severe respiratory distress during these episodes (9).

A non-complicated ventriculoseptal defect was diagnosed concomitantly in our patient; however, since he did not have cardiomegaly in chest radiograph or evidence of pulmonary hypertension in echocardiography, the cardiac defect does not account for the respiratory distress. Nevertheless, it must be kept in mind that untreated upper respiratory tract obstruction may lead to cor pulmonale and cardiac compromise in the long-term (3).

Our patient presented with biphasic stridor, respiratory distress and hyperextension of the neck, all of which are indicative of upper respiratory tract obstruction. In patients not responding to conventional therapies, such as cool mist, nebulised epinephrine or dexamethasone, further investigation is warranted. On the way to a proper diagnosis, radiological studies are of limited value, yet they can identify a mass lesion. However, we should bear in mind that radiological studies cannot diagnose laryngomalacia. With the direct examination of the larynx, a biopsy can be performed leading to a histopathological diagnosis and laryngomalacia and vocal cord paralysis can be identified with direct observation. We want to emphasise that patients presenting with persistent stridor and severe distress necessitate urgent otolaryngologic evaluation.

Ethics Committee Approval: N/A.
Informed Consent: Written informed consent was obtained from the patients for the publication of this case report and any accompanying images.

Peer-review: Externally peer-reviewed.

Author contributions: Concept - Ş.U., P.Z., Ö.M.; Design - I.Y., Ş.U., Ö.M.; Supervision - I.Y., Ş.U., P.Z.; Resource - Ş.U., Ö.M., P.Z., I.Y.; Materials - P.Z., Ş.U., Ö.M.; Data Collection\&/or Processing - Ş.U., I.Y., Ö.M.; Analysis\&/or Interpretation - P.Z., Ş.U., Ö.M.; Literature Search - Ş.U., P.Z., I.Y., Ö.M.; Writing - Ş.U., I.Y., Ö.M.; Critical Reviews - I.Y., Ş.U., P.Z.

Conflict of Interest: No conflict of interest was declared by the authors.

Financial Disclosure: The authors declared that this study has received no financial support.

Video 1. The agitated patient with inspiratory stridor, throwing back his head because of respiratory insufficiency.

\section{REFERENCES}

1. Buckmire RA, Kwon TK. Bilateral obstructing laryngeal epithelial adenomatous hamartomas. Arch Otolaryngol Head Neck Surg 2005;131:259-61. [CrossRef]

2. Daniel SJ. The upper airway congenital malformations. Paediatr Respir Rev 2006;7:260-3. [CrossRef]

3. Fine ED, Dahmas B, Arnold JE. Laryngeal hamartoma: A rare congenital abnormality. Ann Otol Rhinol Laryngol 1995;104:87-9. [CrossRef]

4. Karatas E, Mumbuc S, Durucu C, Kanlıkama M, Bakır K, Ekiz S. Hamartoma of the larynx causing nonspesifik symptoms in the falce vocal cord: Original image. Turkiye Klinikleri J Med Sci 2008;28:252-4.

5. Leung AK, Cho HY. Diagnosis of stridor in children. Am Fam Physician 1999;60:2289-96.

6. Linder A. Hamartoma of the larynx causing neonatal respiratory distress. J Larygol Otol 1997;112:166-8.

7. Makitie AA, Lehtonen H, Back L, Aaltonen LM, Leivo I. Hamartoma of the larynx: An unusual cause of dyspnea. Ann Otol Rhinol Laryngol 2003;112:841-3. [CrossRef]

8. Rinaldo A, Mannara GM, Fisher C, Ferlito A. Hamartoma of the larynx: a critical review of the literature. Ann Otol Rhinol Laryngol 1998;107:264-7. [CrossRef]

9. Yigitbasi OG, Guler G, Ozturk F, Guney E. Glandular hamartoma of the larynx. Int J Pediatr Otorhinolaryngol 2002;65:163-6. [CrossRef] 